\title{
When ruthenia met titania: achieving extraordinary catalytic activity at low temperature by nanostructuring of oxides
}

\author{
J. Graciani, ${ }^{\star a}{ }^{a}$ F. Yang, ${ }^{b}$ J. Evans, ${ }^{c}$ A. B. Vidal, ${ }^{\text {bd }}$ D. Stacchiola, ${ }^{b}$ J. A. Rodriguez ${ }^{b}$ and \\ J. F. Sanz ${ }^{a}$
}

\begin{abstract}
Nanostructured $\mathrm{RuO}_{x} / \mathrm{TiO}_{2}(110)$ catalysts have a remarkable catalytic activity for $\mathrm{CO}$ oxidation at temperatures in the range of $350-375 \mathrm{~K}$. On the other hand, the $\mathrm{RuO}_{2}(110)$ surface has no activity. The state-of-the-art DFT calculations indicate that the main reasons for such an impressive improvement in the catalytic activity are: (i) a decrease of the diffusion barrier of adsorbed $\mathrm{O}$ atoms by around $40 \%$, from $1.07 \mathrm{eV}$ in $\mathrm{RuO}_{2}(110)$ to $0.66 \mathrm{eV}$ in $\mathrm{RuO}_{x} / \mathrm{TiO}_{2}(110)$, which explains the shift of the activity to lower temperatures and (ii) a lowering of the barrier by $20 \%$ for the association of adsorbed $\mathrm{CO}$ and $\mathrm{O}$ species to give $\mathrm{CO}_{2}$ (the main barrier for the $\mathrm{CO}$ oxidation reaction) passing from around $0.7 \mathrm{eV}$ in $\mathrm{RuO}_{2}(110)$ to 0.55 $\mathrm{eV}$ in $\mathrm{RuO}_{x} / \mathrm{TiO}_{2}(110)$. We show that the catalytic properties of ruthenia are strongly modified when supported as nanostructures on titania, attaining higher activity at temperatures $100 \mathrm{~K}$ lower than that needed for pure ruthenia. As in other systems consisting of ceria nanostructures supported on titania, nanostructured ruthenia shows strongly modified properties compared to the pure oxide, consolidating the fact that the nanostructuring of oxides is a main way to attain higher catalytic activity at lower temperatures.
\end{abstract}

www.rsc.org/pccp

Received 5th August 2015, Accepted 3rd September 2015

DOI: $10.1039 / c 5 c p 04638 f$

\section{Introduction}

The removal of pollutants from the exhausts of automobiles is progressively but severely demanded by legislation worldwide. ${ }^{1-3}$ The so-called three-way catalysts used in the exhaust of automobiles try to eliminate at the same time $\mathrm{NO}_{x}$ species, hydrocarbons and $\mathrm{CO}$, transforming them to $\mathrm{N}_{2}, \mathrm{H}_{2} \mathrm{O}$ and $\mathrm{CO}_{2}$ respectively. ${ }^{1-4} \mathrm{CO}$ oxidation is usually taken as the probe reaction for that purpose due to its simplicity and it has been

40 one of the most widely studied heterogeneous catalytic reactions. ${ }^{5}$ Oxidation of carbon monoxide is efficiently catalyzed by platinum group metal surfaces and related precious metals. ${ }^{1,3-5}$ Generally they are supported as small metal particles on refractory oxide supports such as silica $\left(\mathrm{SiO}_{2}\right)$, alumina $\left(\mathrm{Al}_{2} \mathrm{O}_{3}\right)$ ceria $\left(\mathrm{CeO}_{2}\right)$, or refractory alumino-silicate materials like cordierite $\left(2 \mathrm{MgO} \cdot 2 \mathrm{Al}_{2} \mathrm{O}_{3} \cdot 5 \mathrm{SiO}_{2}\right){ }^{3}$ It is generally accepted that $\mathrm{CO}$ and $\mathrm{O}_{2}$ adsorb directly onto the metal surfaces of $\mathrm{Pt}, \mathrm{Rh}$ and $\mathrm{Pd}$ and then the reaction may take place. ${ }^{6}$ However, the reaction mechanism in $\mathrm{Ru}$ is very different. $\mathrm{Ru}(0001)$ is a very poor

${ }^{a}$ Departamento de Quimica Física, Universidad de Sevilla, 41012-Sevilla, Spain ${ }^{b}$ Chemistry Department, Brookhaven National Laboratory, P.O. Box 5000, Upton, NY 11973-5000, USA

${ }^{c}$ Facultad de Ciencias, Universidad Central de Venezuela, Caracas 1020-A, Venezuela

$55{ }^{d}$ Centro de Quimica, Instituto Venezolano de Investigaciones Cientificas (IVIC), Apartado 21827, Caracas 1020-A, Venezuela catalyst for CO oxidation under UHV conditions. ${ }^{7}$ High oxidizing conditions are required to form $\mathrm{RuO}_{x}$ species or $\mathrm{RuO}_{2}$ that then exhibits high catalytic activity. Therefore, contrary to the other precious metals, the active phase in ruthenium catalyzed oxidation reactions is the oxide. ${ }^{7}$

Ruthenia $\left(\mathrm{RuO}_{2}\right)$ is an excellent oxidation catalyst in heterogeneous catalysis at temperatures higher than $400 \mathrm{~K}, 450 \mathrm{~K}$ being the optimum temperature for CO oxidation. ${ }^{8-10}$ The activity of ruthenia is even higher than that of Pt or Pd under excess $\mathrm{O}_{2}$ at atmospheric pressure. ${ }^{11}$ Although the availability of $\mathrm{Ru}$ is limited (about $20 \mathrm{t}$ per year) its lower price compared to the other precious metals (currently the Pt market price is 31.4 $€$ per $\mathrm{g}$, while the $\mathrm{Ru}$ price is $1.5 €$ per $\mathrm{g})^{12}$ makes it a good candidate for an eventual substitution of the usual Pt particles by $\mathrm{RuO}_{2}$ particles in the exhaust catalysts in the automobile industry. Rh is even more expensive than Pt (31.75 € per g), and Pd is still costlier with $19.97 €$ per g (13 times more expensive than $\mathrm{Ru}) .{ }^{12}$ Therefore, it seems interesting trying to design a ruthenia-based catalytic system with at least similar catalytic activity than the usual Pt-based catalysts.

Recently we have shown that $\mathrm{RuO}_{2}$ grows on $\mathrm{TiO}_{2}(110)$ forming nanowires that have special chemical properties. ${ }^{13} \mathrm{~A}$ reversible $\mathrm{RuO}_{2} \leftrightarrow \mathrm{Ru}$ transformation was observed when the temperature and background $\mathrm{O}_{2}$ pressure were changed. ${ }^{13}$ Fig. 1 displays data for the oxidation of $\mathrm{CO}$ on $\mathrm{RuO}_{2} / \mathrm{TiO}_{2}(110)$ surfaces at 350 and $375 \mathrm{~K}$. This is quite remarkable since at these 

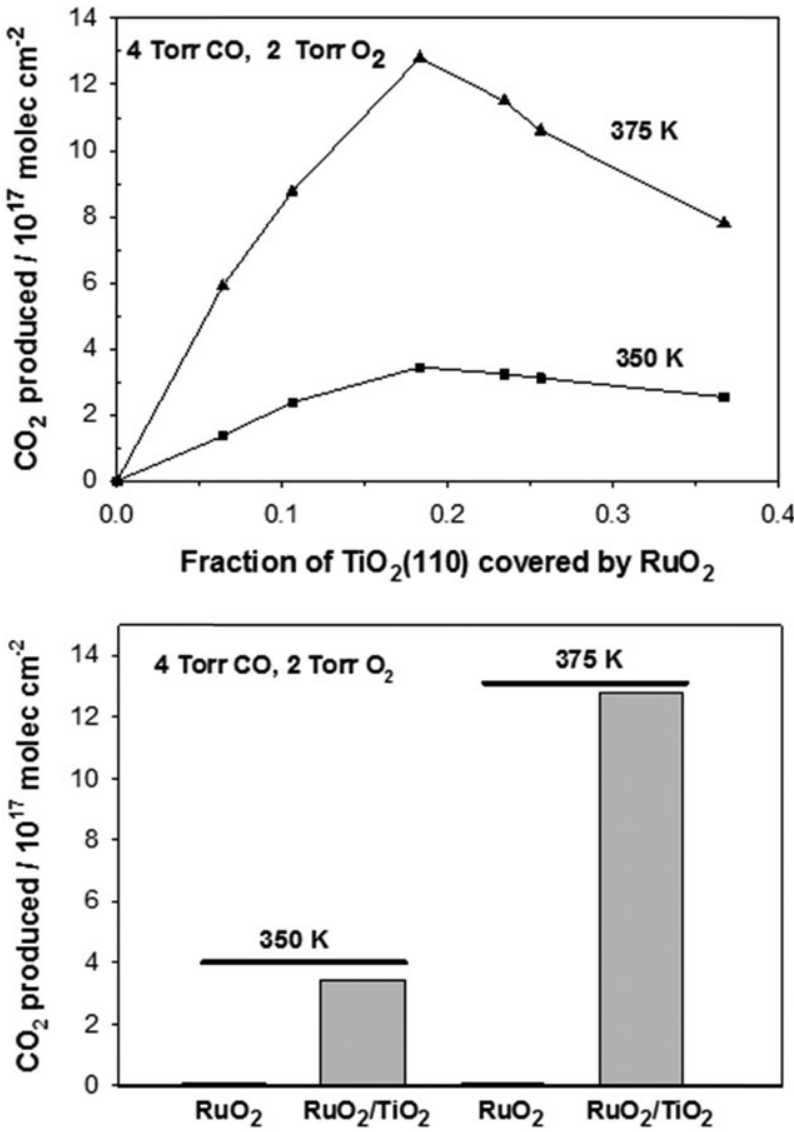

Fig. 1 Top: $\mathrm{CO}$ oxidation activity of $\mathrm{RuO}_{2} / \mathrm{TiO}_{2}(110)$ as a function of $\mathrm{RuO}_{2}$ coverage. The area of the titania substrate covered by $\mathrm{RuO}_{2}$ was measured by ion scattering spectroscopy before carrying out the oxidation of $\mathrm{CO}$. The reported values for the production of $\mathrm{CO}_{2}$ were obtained after exposing the catalysts to 4 Torr $\mathrm{CO}$ and 2 Torr $\mathrm{O}_{2}$ at 350 or $375 \mathrm{~K}$ for $5 \mathrm{~min}$. Bottom: A comparison of the activity for $\mathrm{CO}$ oxidation of the $\mathrm{RuO}_{2}(110)$ and $\mathrm{TiO}_{2}(110)$ surfaces covered by about $18 \%$ with $\mathrm{RuO}_{2}$ nanowires. XPS spectra showed only $\mathrm{Ru}^{4+}$ before and after $\mathrm{CO}$ oxidation.

temperatures $\mathrm{TiO}_{2}(110)$ surfaces are not catalytically active, ${ }^{13}$ while $\mathrm{RuO}_{2}(110)$ surfaces have low activity, ${ }^{8,13}$ achieving their highest activity at temperatures around $450 \mathrm{~K}{ }^{8}$ The change has $\mathrm{TiO}_{2}(110)$. An analogous amazing catalytic effect has been observed for another nanostructured oxide supported on titanium dioxide: $\mathrm{CeO}_{x} / \mathrm{TiO}_{2}(110) .{ }^{14-16}$ In that case the strong interaction with the support changed the electronic and geometrical $\mathrm{Ce}_{2} \mathrm{O}_{3}$ dimers highly dispersed all over the surface. Obviously, the redox properties and the catalytic activity of these strongly modified $\mathrm{CeO}_{x}$ species were completely different from those of the $\mathrm{CeO}_{2}$ (111) surface. ${ }^{17}$ The resulting system showed tremendous catalytic activity for the water gas shift reaction, CO oxidation, and methanol synthesis from $\mathrm{CO}_{2}$, when combined with metal nanoparticles. ${ }^{14-16}$

Similar catalytic effects may be expected for supported $\mathrm{RuO}_{x}$ species by nanostructuring of oxides. However, different from the $\mathrm{CeO}_{x} / \mathrm{TiO}_{2}(110)$ system, for the $\mathrm{RuO}_{x} / \mathrm{TiO}_{2}(110)$ catalyst only structural optimizations and global energy trends have been calculated. ${ }^{13}$ In our previous paper we characterized the system by means of STM, XPS and some DFT calculations, concluding that it consists of $\mathrm{RuO}_{2}$ wire-like structure on $\mathrm{TiO}_{2}(110) .{ }^{13}$ But why the system reaches that high activity at much lower temperature than pure ruthenia is still unexplained.

In contrast, the mechanism for $\mathrm{CO}$ oxidation on $\mathrm{RuO}_{2}(110)$ has been widely studied. ${ }^{10}$ The chemical nature of the interaction of $\mathrm{CO}$ and $\mathrm{O}_{2}$ with the ruthenia surface is well known and the main barriers for the reaction have been determined. ${ }^{10}$ On the other hand, the reactivity of $\mathrm{TiO}_{2}(110)$ against $\mathrm{CO}$ and $\mathrm{O}_{2}$ is negligible since the adsorption of $\mathrm{CO}$ is very weak (the strongest adsorbed CO molecules desorb above $170 \mathrm{~K}),{ }^{18}$ and the $\mathrm{O}_{2}$ molecule does not adsorb onto the stoichiometric $\mathrm{TiO}_{2}(110)$ surface. ${ }^{19}$ Therefore, if the $\mathrm{RuO}_{x} / \mathrm{TiO}_{2}(110)$ catalyst is more active than the $\mathrm{RuO}_{2}(110)$ surface the reason has to be in the modifications induced by the titania in the chemistry of the supported nanostructured ruthenia. In this work we compare the chemical behavior and the main CO oxidation reaction barriers of the $\mathrm{RuO}_{x} / \mathrm{TiO}_{2}(110)$ system with those of the very well-known pure $\mathrm{RuO}_{2}(110)$ surface.

\section{Computational methods}

We model the $\mathrm{RuO}_{2}(110)$ surface with four O-Ru-O threelayers, keeping the two of the bottom fixed at the optimized bulk positions, allowing a vacuum region of $15 \AA$ between the repeated slabs. In order to avoid lateral interactions or effects coming from a high coverage, a $(6 \times 2)$ surface model was used. The nanostructured ruthenia on titania was modelled as follows: (a) the $\mathrm{TiO}_{2}(110)$ surface consisted of four O-Ti-O threelayers, with the two of the bottom fixed at the optimized bulk positions, allowing a vacuum region of $15 \AA$ between the repeated slabs; (b) in order to achieve an isolated wire-like $\mathrm{RuO}_{2}(110)$ nanostructure a $(6 \times 3)$ surface model of the titania support was used; (c) a fully relaxed three atomic layer width $(\mathrm{O}-\mathrm{Ru}-\mathrm{O})$ wire $(6 \times 1)$ was coupled to the titania support according to ref. 13. The Perdew-Wang 91 (PW91) functional ${ }^{20}$ was used for the exchange-correlation potential. The effect of the core electrons on the valence states was determined using the projector-augmented wave (PAW) approach, ${ }^{21}$ as implemented in the Vienna ab initio simulation package, (VASP 5.3), ${ }^{22,23}$ with the valence states defined for each atom as Ti (3s, 3p, 3d, $4 \mathrm{~s}), \mathrm{Ru}(4 \mathrm{~s}, 4 \mathrm{p}, 4 \mathrm{~d}, 5 \mathrm{~s}), \mathrm{C}(2 \mathrm{~s}, 2 \mathrm{p}), \mathrm{O}(2 \mathrm{~s}, 2 \mathrm{p})$, and $\mathrm{H}(1 \mathrm{~s})$ electrons, while the remaining electrons were kept frozen as core states. The valence electronic states are expanded in a basis of plane waves with a cutoff of $400 \mathrm{eV}$ for the kinetic energy. In order to account for the eventual reduction of the titania support (occupation of Ti 3d states) a Hubbard-like U term was used, (GGA+U), according to Dudarev et al.'s implementation, ${ }^{24}$ which makes use of an effective parameter $U_{\text {eff }}$. We took a value $U_{\text {eff }}=4.5 \mathrm{eV}$ satisfactorily used in our previous studies dealing with supported cerium oxide particles on titania. ${ }^{15-17,25}$ Calculations were performed at the $\Gamma$ point of the Brillouin zone. The transition states were found by the climbing nudged elastic band method (cNEB). 


\section{Experimental methods}

\section{Microscopy and catalytic tests}

Clean $\mathrm{TiO}_{2}(110)$ surfaces were prepared by repeated cycles of argon-ion sputtering and annealing to $900 \mathrm{~K}$ in the presence of oxygen. Following previous studies, ${ }^{13} \mathrm{Ru}_{3}(\mathrm{CO})_{12}$ was used as a precursor for the deposition of ruthenium. $\mathrm{Ru}_{3}(\mathrm{CO})_{12}$ vapor was introduced into the chamber using a doser, increasing the chamber pressure to $1 \times 10^{-8}$ Torr. While dosing the carbonyl, the $\mathrm{TiO}_{2}$ crystal was held at $300 \mathrm{~K}$ with subsequent heating at elevated temperatures $(600-700 \mathrm{~K})$ in $\mathrm{O}_{2}$ to induce the formation of $\mathrm{RuO}_{x}$. This procedure does not leave $\mathrm{C}$ on the surface, since the final treatment involves oxidation in an $\mathrm{O}_{2}$ background. The area of the titania surface covered by $\mathrm{RuO}_{x}$ was estimated using STM images and/or a combination of ISS and XPS. It is interesting to note that a different synthesis method based on depositing $\mathrm{Ru}$ from an electron beam evaporator led to the formation of extended films of $\mathrm{RuO}_{2}$ instead of nanostructured $\mathrm{RuO}_{2}$ wires. ${ }^{26}$ Microscopy studies were carried out using an Omicron variable temperature STM system. Chemically etched tungsten tips were used for imaging. Tests of catalytic activity for $\mathrm{CO}$ oxidation were conducted in a system which combines a batch reactor and a UHV chamber. ${ }^{13-16}$ This UHV chamber (base pressure $c a .1 \times 10^{-10}$ Torr) was equipped with instrumentation for X-ray photoelectron spectroscopy, low-energy electron diffraction, ion scattering spectroscopy, and temperature programmed desorption. Typically, the sample was transferred from the UHV chamber to the batch reactor at about $300 \mathrm{~K}$ without exposure to air. The reactant gases were introduced (4 Torr $\mathrm{CO}$ and 2 Torr $\mathrm{O}_{2}$ ), and then the sample was rapidly heated to the reaction temperature of 350 or $375 \mathrm{~K}$. The amount of molecules produced was normalized by the active area exposed by the sample.

\section{Results and discussion}

First of all, we show the geometrical structure of the system as determined by STM experimental images and DFT calculations ${ }^{13}$ and we compare new DFT-simulated STM images with the experimental ones (Fig. 2). $\mathrm{RuO}_{x}$ species supported on $\mathrm{TiO}_{2}(110)$

40 are wire-like nanostructures epitaxially grown on the rutile structure showing the (110) surface. They coexist with some nanowires of $\mathrm{TiO}_{x}$ which exhibit a different height. ${ }^{13}$ In $\mathrm{RuO}_{x}$ nanowires, the well-known O bridging $\left(\mathrm{O}_{\mathrm{br}}\right)$ row of the $\mathrm{RuO}_{2}(110)$ surface is in the middle of the wire and two rows of fivefold coordinated $\mathrm{Ru}$ atoms 45 (traditionally called coordinatively unsaturated, cus, $\left.\mathrm{Ru}_{\mathrm{cus}}\right)^{10}$ are parallel on both sides of the $\mathrm{O}_{\mathrm{br}}$ row (see Fig. 2). In order to clearly and coherently state the nomenclature, we use the subscript " $5 \mathrm{c}$ " to refer to fivefold coordinated metal atoms of the surface, either $\mathrm{Ru}_{5 \mathrm{c}}$ (traditionally $\mathrm{Ru}_{\text {cus }}$ ) or $\mathrm{Ti}_{5 \mathrm{c}}$; analogously, we will call fully coordinated metal atoms (six-fold coordinated) " $6 \mathrm{c}$ ", either $\mathrm{Ru}_{6 \mathrm{c}}$ or $\mathrm{Ti}_{6 \mathrm{c}}$; the undercoordinated oxygen atoms of the surface are called, as usual, bridging atoms, with a subscript "br", $\mathrm{O}_{\mathrm{br}}$; finally, all remaining oxygen atoms are simply labelled $\mathrm{O}$.

In the STM image of the supported wire, the brightest spot row in the middle corresponds to $\mathrm{O}_{\mathrm{br}}$ atoms above the wire, while the other bright shadows on each side of the $\mathrm{O}_{\mathrm{br}}$ row
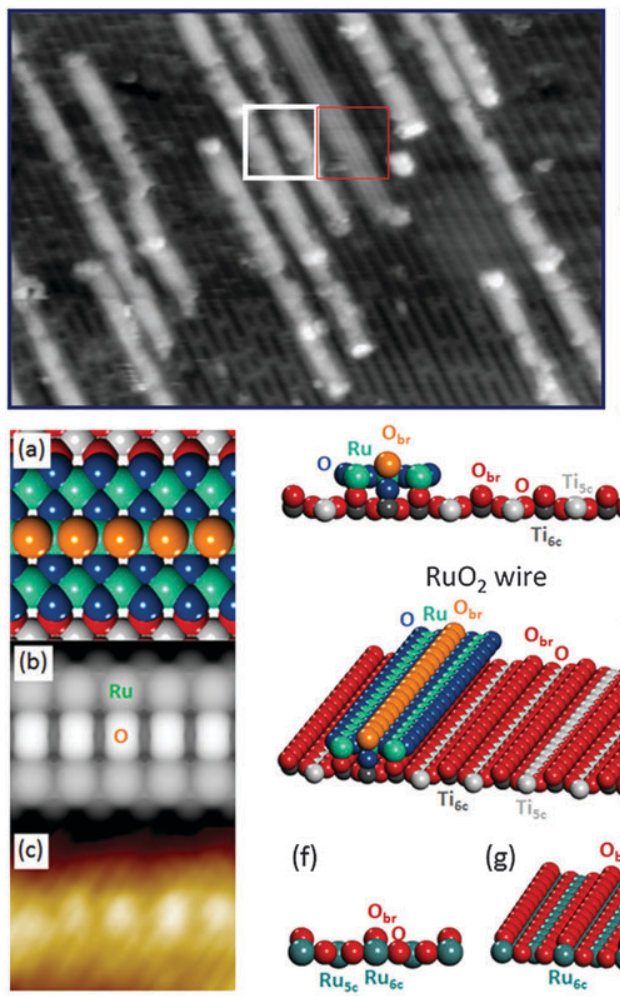

(f)

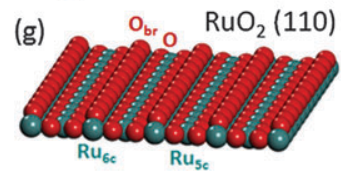

Fig. 2 Top: STM image of a small coverage of $\mathrm{RuO}_{2}$ on $\mathrm{TiO}_{2}(110)(30 \mathrm{~nm} \times$ $\left.20 \mathrm{~nm} ; V_{\mathrm{t}}=1.5 \mathrm{~V} ; I_{\mathrm{t}}=1.2 \mathrm{nA}\right)$. The insets on the right side magnify in detail the structures of $\mathrm{RuO}_{2}$ (white or black boxes) and $\mathrm{TiO}_{x}$ (red boxes). The original STM images were published before (ref. 13), here we present those results for comparing more clearly with the new DFT results. Bottom: geometry of wire-like nanostructured $\mathrm{RuO}_{2}(110)$ supported on the $\mathrm{TiO}_{2}(110)$ surface. (a) Top view of the atomic representation of the wire, (b) DFT-simulated STM image of the wire, (c) experimental STM image of the wire, (d) side view of the $\mathrm{RuO}_{2}$ wire supported on $\mathrm{TiO}_{2}(110)$, (e) 3D view of the same system, ( $f$ and $g$ ) side and 3D views of the $\mathrm{RuO}_{2}(110)$ surface. Colors: $\mathrm{O}$ atoms of pure $\mathrm{RuO}_{2}(110)$ and $\mathrm{TiO}_{2}(110)$ surfaces (red), $\mathrm{O}_{\mathrm{br}}$ on top of the $\mathrm{RuO}_{2}$ wire (orange), remaining $\mathrm{O}$ atoms of the wire (blue), $\mathrm{Ti}_{5 c}$ (soft gray), $\mathrm{Ti}_{6 c}$ (dark gray), $\mathrm{Ru}$ atoms in the wire (light green), and Ru atoms in the $\mathrm{RuO}_{2}(110)$ surface (dark green). Only the outermost atoms of the system are represented for the sake of simplicity.

correspond to $\mathrm{Ru}_{5 \mathrm{c}}$ atoms of the wire. In the part of the STM image taken over the $\mathrm{TiO}_{2}(110)$-support surface, the bright lines correspond, as usual, to the $\mathrm{Ti}_{5 \mathrm{c}}$ rows of the oxide surface.

$\mathrm{CO}$ oxidation catalyzed by this system was efficiently carried out at 350 or $375 \mathrm{~K}$ (Fig. 1). According to the abundant literature, the active sites for the chemistry of the $\mathrm{RuO}_{2}(110)$ surface are the $\mathrm{Ru}_{5 \mathrm{c}}$ sites. At those sites, $\mathrm{O}_{2}$ adsorbs and dissociates readily giving two $\mathrm{O}$ atoms adsorbed on top of two $\mathrm{Ru}_{5 \mathrm{c}}$ sites, and $\mathrm{CO}$ adsorbs strongly at the same position. ${ }^{10}$ According to the ample bibliography, there are three main factors that influence the catalytic activity of the $\mathrm{RuO}_{2}(110)$ surface. ${ }^{10}$ (1) High diffusion energy barriers (higher than $1 \mathrm{eV}$ ) for both $\mathrm{O}$ and $\mathrm{CO}$ adsorbed species. Such barriers justify that only above $400 \mathrm{~K}$, when adsorbed species are able to diffuse, the catalytic activity starts to be high, reaching a maximum value at $450 \mathrm{~K}$. (2) The main reaction energy barrier which corresponds to the association of the adsorbed $\mathrm{O}$ and $\mathrm{CO}$ species to give $\mathrm{CO}_{2}$, being around
5

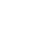


$1 \quad 0.8-0.9 \mathrm{eV}$. (3) The stoichiometric ratio of reactants $\left(\mathrm{O}_{2}: 2 \mathrm{CO}\right)$, since both are competing for the same reactive sites, namely $\mathrm{Ru}_{5 \mathrm{c}}$ (high $\mathrm{O}_{2}$ pressure saturates the surface avoiding the $\mathrm{CO}$ adsorption; high CO pressure not only saturates the surface against $\mathrm{O}_{2}$ adsorption but may also reduce, even completely, the whole surface giving metallic $\mathrm{Ru}$ clusters at temperatures above $400 \mathrm{~K}^{27}$ ). As we are using a stoichiometric ratio of $\mathrm{O}_{2}$ and $\mathrm{CO}$, the higher activity of the $\mathrm{TiO}_{2}$-supported nanostructured $\mathrm{RuO}_{2}$ over the $\mathrm{RuO}_{2}(110)$ surface has to come from the lowering of either the diffusion barriers or the $\mathrm{O}-\mathrm{CO}$ association barrier.

We have calculated these energy barriers on the $\mathrm{RuO}_{2}(110)$ surface and $\mathrm{TiO}_{2}$-supported wire-like $\mathrm{RuO}_{2}$ nanostructures. The geometries and energies of the most significant transition states are presented in Fig. 3. The most important change is observed for the energy barrier of the diffusion of adsorbed $\mathrm{O}$ atoms along the $\mathrm{Ru}_{5 \mathrm{c}}$ rows. We obtained a value of $1.07 \mathrm{eV}$ for the O-diffusion on $\mathrm{RuO}_{2}(110)$ that lowers to $0.66 \mathrm{eV}$ in the wirelike $\mathrm{RuO}_{2}$ supported nanostructures. This tremendous decrease (around $40 \%$ ) of the diffusion barrier explains by itself the drop in the operating temperature from $450 \mathrm{~K}$ to $350 \mathrm{~K}$. While adsorbed $\mathrm{O}$ atoms cannot diffuse on $\mathrm{RuO}_{2}(110)$ at $350 \mathrm{~K}$ they can do it readily on nanostructured $\mathrm{RuO}_{2}$ supported on $\mathrm{TiO}_{2}(110)$. However, the diffusion barrier for adsorbed CO remains unchanged: $1.45 \mathrm{eV}$ in $\mathrm{RuO}_{2}$ (110) and $1.44 \mathrm{eV}$ in $\mathrm{RuO}_{2} / \mathrm{TiO}_{2}(110)$. To have the $\mathrm{CO}$ oxidation reaction running we only need that one of the two (O or $\mathrm{CO}$ ) is able to move to reach the other and then react. Therefore, in the nanostructured $\mathrm{RuO}_{2} / \mathrm{TiO}_{2}(110)$ system the motion of adsorbed $\mathrm{O}$ atoms enables the reaction to be able to start at lower temperatures.

The reason for the decrease in the diffusion barrier for the adsorbed $\mathrm{O}$ atom is double. First, as it can be seen in Fig. 3, the motion of the adsorbed $\mathrm{O}$ atom from one $\mathrm{Ru}_{5 \mathrm{c}}$ to the other implies a large structural deformation of the $\mathrm{O}$ atoms around.
They move inward repelled by the passing $\mathrm{O}$ anion. Obviously, this distortion is much easier to happen in a non-periodic structure (such as the wire-like structure) than in a periodic $2 \mathrm{D}$ structure such as pure $\mathrm{RuO}_{2}(110)$ or $1 \mathrm{ML}$ of extended $\mathrm{RuO}_{2}$ on $\mathrm{TiO}_{2}(110)$, where the $x-y$ relaxations are really hindered. Indeed, in our wire-like structure, one of the two $\mathrm{O}$ atoms that has to move inward (the outermost one) is free to do it since it is bonded only to two $\mathrm{Ru}_{5 \mathrm{c}}$ instead of three (see Fig. 3). The second reason is that the distance of $\mathrm{Ru}-\mathrm{Ru}$ is shortened by around $5 \%$ in the 001 direction due to the epitaxial growth on $\mathrm{TiO}_{2}(110)$. That means the $\mathrm{Ru}-\mathrm{O}-\mathrm{Ru}$ bridging transition state is easier to form. On the other hand, the unchanged CO diffusion barrier is due to the Blyholder bonding mechanism that takes place in the $\mathrm{CO}-\mathrm{RuO}_{2}$ bond. ${ }^{10}$ This mechanism is tremendously directional: it is maximized in the direction perpendicular to the surface, the CO molecule being just on top of the $\mathrm{Ru}_{5 \mathrm{c}}$ atoms. It has been shown that $\mathrm{Ru}_{5 \mathrm{c}}$ atoms of the surface possess a "dangling bond" $\left(\mathrm{eg}^{2} \mathrm{sp}^{3}\right)$ pointing outward the surface that contributes to the $\sigma$-donation part of the Blyholder mechanism while the $\pi$-back-donation involves mixed $\mathrm{d}_{x z}+\mathrm{d}_{y z}$ Ru orbitals. ${ }^{10}$ This mechanism is highly weakened when the CO molecule moves to the bridging position between two $\mathrm{Ru}_{5 \mathrm{c}}$ in the transition state geometry. This Blyholder-bond breaking should happen equally in both $\mathrm{RuO}_{2}(110)$ and $\mathrm{TiO}_{2}$-supported $\mathrm{RuO}_{2}$ nanostructures, and that is why the diffusion barrier for CO remains unchanged.

Returning to Fig. 3, we can see a significant decrease in the main reaction energy barrier: the $\mathrm{O}-\mathrm{CO}$ association step. This barrier lowers from $0.69 \mathrm{eV}$ in $\mathrm{RuO}_{2}(110)$ to $0.55 \mathrm{eV}$ in $\mathrm{RuO}_{2} /$ $\mathrm{TiO}_{2}(110)$, which means a lowering of $20 \%$ in the association barrier. Therefore, not only the operating temperature drops by around $100 \mathrm{~K}$ (due to the decrease of the $\mathrm{O}$ diffusion barrier by $40 \%$ ) but also higher catalytic activity is expected because of the

\section{$\mathbf{O}$ diffusion}

\section{$\mathrm{O}+\mathrm{CO}$ association}

$\mathrm{RuO}_{2}(110)$

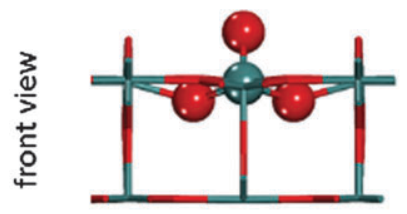

$1.07 \mathrm{eV}$

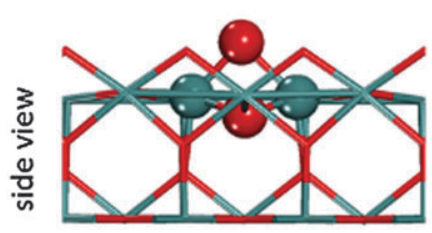

$\mathrm{RuO}_{2} / \mathrm{TiO}_{2}(110)$

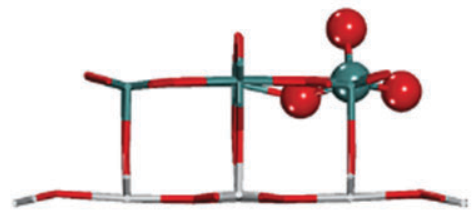

$0.66 \mathrm{eV}$

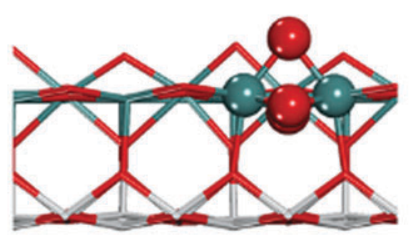

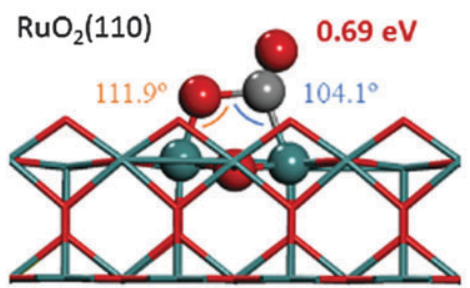

$0.55 \mathrm{eV}$

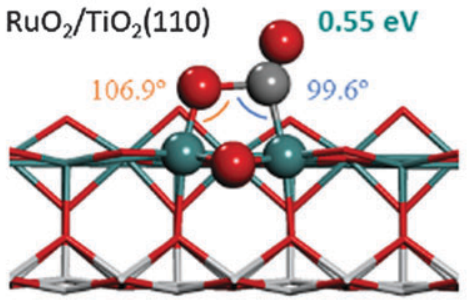

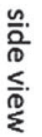
adsorbed species (right figures), for both the $\mathrm{RuO}_{2}(110)$ surface and $\mathrm{RuO}_{2} / \mathrm{TiO}_{2}(110)$ nanostructured oxide. Energy values: $\mathrm{RuO}(110)(\mathrm{red})$ and $\mathrm{RuO} \mathrm{O}_{2} /$ $\mathrm{TiO}_{2}(110)$ (green). Only the atoms directly implied in the transition state geometry are depicted as spheres, the others are shown as sticks. Colors: oxygen (red), ruthenium (green), titanium (light gray) and carbon (dark gray). In the $\mathrm{O}+\mathrm{CO}$ association transition states, the main angles are marked in orange and blue. 
1 reduction of the association barrier by $20 \%$. Again, the explanation for the decrease of the association barrier is mainly related to the shortened $\mathrm{Ru}-\mathrm{Ru}$ distance in the 001 direction in the supported wire-like ruthenia nanostructures compared to pure ruthenia. Lesser structural deformation of the initial $\mathrm{Ru}_{5 \mathrm{c}}-\mathrm{O}$ and $\mathrm{Ru}_{5 \mathrm{c}}-\mathrm{CO}$ bonds is required to reach the transition state geometry on $\mathrm{RuO}_{2} / \mathrm{TiO}_{2}(110)$ than in $\mathrm{RuO}_{2}(110)$ as $\mathrm{O}$ and $\mathrm{CO}$ adsorbed species are closer in the supported ruthenia. This effect can be easily seen comparing the angles of the $\mathrm{Ru}_{5 \mathrm{c}}-\mathrm{C}_{\mathrm{ads}}$

$10 \mathrm{O}_{\mathrm{ads}}$ and $\mathrm{Ru}_{5 \mathrm{c}}-\mathrm{O}_{\mathrm{ads}}-\mathrm{C}_{\mathrm{ads}}$ bonds (where the subscript ads stands for adsorbed) of the transition state geometry in both $\mathrm{RuO}_{2}(110)$ and $\mathrm{RuO}_{2} / \mathrm{TiO}_{2}(110)$. Higher angles imply more strain of the $\mathrm{Ru}_{5 \mathrm{c}}-\mathrm{O}$ and $\mathrm{Ru}_{5 \mathrm{c}}-\mathrm{CO}$ initial bonds to form the transition state geometry (see Fig. 3). The angles of the $\mathrm{Ru}_{5 c^{-}}$

$15 \mathrm{C}_{\mathrm{ads}}-\mathrm{O}_{\text {ads }}$ bond were $104.1^{\circ}$ and $99.6^{\circ}$ for $\mathrm{RuO}_{2}(110)$ and $\mathrm{RuO}_{2} /$ $\mathrm{TiO}_{2}(110)$ respectively. Analogously for the $\mathrm{Ru}_{5 \mathrm{c}}-\mathrm{O}_{\mathrm{ads}}-\mathrm{C}_{\mathrm{ads}}$ bond we obtained angles of $111.9^{\circ}$ and $106.9^{\circ}$. First, we see a lesser strain in the geometry of the transition state in the titaniasupported ruthenia than in pure ruthenia due to the shorter $\mathrm{Ru}-\mathrm{Ru}$ distance. This explains the decrease in the association barrier on the nanostructured ruthenia. Second, we observe that the angle centered in the $\mathrm{C}$ atom is always smaller than the angle centered in the $\mathrm{O}$ atom. This is due to the different bonding mechanism. As the CO bonding mechanism is of the Blyholder type, slight deviations from $90^{\circ}$ imply a fast increase of the energy of the system, while the less orientation demanding $\mathrm{O}$ bond allows for a higher deformation at the same energy cost.

\section{Conclusions}

We have determined why nanostructured titania-supported ruthenia achieves higher catalytic activity for CO oxidation than pure ruthenia at much lower temperatures. Basically, the titania support imposes an epitaxial growth to supported ruthenia showing the (110) face and generating wire-like ruthenia nanostructures. This structurally modified ruthenia has a $\mathrm{Ru}-\mathrm{Ru}$ distance shortened by $5 \%$ in the 001 direction, which propitiates a lower energy barrier for the formation of the O-CO transition state to give $\mathrm{CO}_{2}$ (a decrease by 20\%) and for the diffusion of adsorbed $\mathrm{O}$ atoms along that direction (a decrease around $40 \%$ ). A larger lowering of the O-diffusion barrier arises from an additional stabilizing factor: the motion of the a $\mathrm{O}$ atoms implies a bio structural deformation of the other nearby $\mathrm{O}$ atoms, and this structural distortion is much easier in a discrete nanostructure than in a pure perfect extended surface, in which the $x-y$ relaxations are highly hindered. The huge decrease in the diffusion barrier makes it possible for the reaction to occur at $350 \mathrm{~K}$, instead of the temperature of $450 \mathrm{~K}$ needed for the pure (110) ruthenia surface. The reduction of the $\mathrm{O}+\mathrm{CO}$ association energy barrier by $20 \%$ also enables the nanostructured ruthenia to achieve higher catalytic activity than pure ruthenia. As in other systems studied before consisting of ceria nanostructures supported on titania, ${ }^{14-16}$ nanostructured ruthenia on titania shows strongly modified properties compared to the pure oxide, consolidating the fact that nanostructuring of oxides is a main way to attain new catalysts with higher activity at lower temperatures.

\section{Acknowledgements}

This work was funded by the Ministerio de Economía y Competitividad, Spain (grant MAT2012-31526), EU COST CM1104, and EU FEDER. Computational resources were provided by the Barcelona Supercomputing Center/Centro Nacional de Supercomputación (Spain). The research carried out at the Brookhaven National Laboratory was supported by the Division of Chemical Sciences, Geosciences, and Biosciences, Office of Basic Energy Sciences of the U.S. Department of Energy under contract DEAC02-98CH10886. J.E. thanks INTEVEP and IDB for research grants that made possible part of this work at the Universidad Central de Venezuela.

\section{References}

1 H. S. Gandhi, G. W. Graham and R. W. McCabe, J. Catal., 2003, 216, 433.

2 M. Bowker, Chem. Soc. Rev., 2008, 37, 2204.

3 H. Abe, Science and Technology Trends - Quarterly Review, 2011, vol. 39, p. 21.

4 Y. Nishihata, J. Mizuki, T. Akao, H. Tanaka, M. Uenishi, M. Kimura, T. Okamoto and N. Hamada, Nature, 2002, 418, 164 .

5 A. W. Santra and D. W. Goodman, Electrochim. Acta, 2002, 47, 3595.

6 T. Engel and G. Ertl, The Chemical Physics of Solid Surfaces and Heterogeneous Catalysis, ed. D. A. King and D. P. Woodruff, Elsevier, Amsterdam, vol. 4, 1982.

7 Y. D. Kim, H. Over, G. Krabbes and G. Ertl, Top. Catal., 2001, 14, 95.

8 R. Blume, M. Hävecker, S. Zafeiratos, D. Teschner, A. KnopGericke, R. Schögl, P. Dudin, A. Barinov and M. Kiskinova, Catal. Today, 2007, 124, 71.

9 H. Over, Y. D. Kim, A. P. Seitsonen, S. Wendt, E. Lundgren, M. Schmid, P. Varga, A. Morgante and G. Ertl, Science, 2000, 287, 1474.

10 H. Over, Chem. Rev., 2012, 112, 3356.

11 N. W. Cant, P. C. Hicks and B. S. Lennon, J. Catal., 1978, 54, 372 .

12 http://www.infomine.com/investment/metal-prices/, November 7th 2014.

13 F. Yang, S. Kundu, A. B. Vidal, J. Graciani, P. J. Ramirez, S. D. Senanayake, D. Stacchiola, J. Evans, P. Liu and J. F. Sanz, et al., Angew. Chem., Int. Ed., 2011, 50, 10198.

14 J. Graciani, K. Mudiyanselage, F. Xu, A. E. Baber, J. Evans, S. D. Senanayake, D. J. Stacchiola, P. Liu, J. Hrbek and J. F. Sanz, et al., Science, 2014, 345, 546.

15 J. B. Park, J. Graciani, J. Evans, D. Stacchiola, S. Ma, P. Liu, A. Nambu, J. F. Sanz, J. Hrbek and J. A. Rodriguez, Proc. Natl. Acad. Sci. U. S. A., 2009, 106, 4975. 
116 J. B. Park, J. Graciani, J. Evans, D. Stacchiola, S. D. Senanayake, L. Barrio, P. Liu, J. F. Sanz, J. Hrbek and J. A. Rodriguez, J. Am. Chem. Soc., 2010, 132, 356.

17 J. Graciani, J. J. Plata, J. F. Sanz, P. Liu and J. A. Rodriguez, J. Chem. Phys., 2010, 132, 104703.

18 C. L. Pang, R. Lindsay and G. Thornton, Chem. Rev., 2013, 113, 3887.

19 C. L. Pang, R. Lindsay and G. Thornton, Chem. Soc. Rev., 2008, 37, 2328.

20 J. Perdew and Y. Wang, Phys. Rev. B: Condens. Matter Mater. Phys., 1992, 45, 13244.

21 G. Kresse and J. Joubert, Phys. Rev. B: Condens. Matter Mater. Phys., 1999, 59, 1758.
22 G. Kresse and J. Hafner, Phys. Rev. B: Condens. Matter Mater. Phys., 1993, 47, 558.

23 G. Kresse and J. Furthmuller, Comput. Mater. Sci., 1996, 6, 15. 24 S. L. Dudarev, G. A. Botton, S. Y. Savrasov, C. J. Humphreys and A. P. Sutton, Phys. Rev. B: Condens. Matter Mater. Phys., 1998, 57, 1505.

25 A. C. Johnston-Peck, S. D. Senanayake, J. J. Plata, S. Kundu, W. Xu, L. Barrio, J. Graciani, J. F. Sanz, R. M. Navarro and J. L. Fierro, et al., J. Phys. Chem. C, 2013, 117, 14463.

26 Y. He, D. Langsdorf, L. Li and H. Over, J. Phys. Chem. C, 2015, 119, 2692.

27 Y. B. He, M. Knapp, E. Lundgren and H. Over, J. Phys. Chem. B, 2005, 109, 21825. 